\title{
Occurrence and properties of soils on sandy beach ridges in the Kelantan-Terengganu Plains, Peninsular Malaysia
}

\begin{abstract}
A study was conducted along the Kelantan-Terengganu Coastal Plains, Peninsular Malaysia to explain the occurrence of sandy beach ridges and to determine the physico-chemical properties of the soils formed on them. Two or occasionally three series of sandy ridges running parallel to the shoreline occur in the area. These ridges are believed to have been formed by the continuous action of the sea waves following changes in the sea level during the Holocene, the oldest ridge being the one farthest away from the shoreline. In between these ridges occurs a slight depression, usually occupied by soils under submerged condition. The soils on the ridges are subjected to the processes of soil formation, mainly podzolization. There is no horizon differentiation in the soils on the ridge nearest to the shoreline. However, soils on the older ridges contain spodic horizon, occurring at varying depths. Drainage and the depth below which this spodic horizon occurs are the deciding factors for determining soil type (series). Physically, the soils are sandy containing $>95 \%$ sand, with the drainage varying from moderately well to excessively-drained for the soils on the ridges. Under this condition, the mineralogy of the clay and silt fractions is dominated by quartz; some feldspars, mica, kaolinite, gibbsite and anatase are also present. Sandy nature of the soils on beach ridges, extreme leaching, low cation exchange capacity and low exchangeable bases leads to their low productivity.
\end{abstract}

Keyword: Sandy beach ridges; Spodic horizon; Podzolization; Tropical climate 